\title{
Analyzing COVID-19 Impact on the Researchers Productivity through Their Perceptions
}

\author{
Syeda Javeria Shoukat ${ }^{1}$, Humaira Afzal $^{2}$, Muhammad Rafiq Mufti ${ }^{3}$, Muhammad Khalid Sohail ${ }^{4}$, \\ Dost Muhammad Khan ${ }^{5}$, Nadeem Akhtar ${ }^{5}$, Shahid Hussain ${ }^{6, *}$ and Mansoor Ahmed
}

\author{
${ }^{1}$ Department of Computer Science, COMSATS University, Islamabad, 45550, Pakistan \\ ${ }^{2}$ Department of Computer Science, Bahauddin Zakariya University, Multan, 60800, Pakistan \\ ${ }^{3}$ Department of Computer Science, COMSATS University Islamabad, Vehari Campus, Islamabad, 61100, Pakistan \\ ${ }^{4}$ Department of Management Studies, Bahria Business School, Bahria University, Islamabad, 44000, Pakistan \\ ${ }^{5}$ Department of Computer Science \& IT, The Islamia University of Bahawalpur, Bahawalpur, 63100, Pakistan \\ ${ }^{6}$ Department of Computer and Information Science, University of Oregon, Eugene, OR, 97401, USA \\ ${ }^{*}$ Corresponding Author: Shahid Hussain. Email: shussain@uoregon.edu \\ Received: 18 September 2020; Accepted: 29 November 2020
}

\begin{abstract}
Context: Since the end of 2019, the COVID-19 pandemic had a worst impact on world's economy, healthcare, and education. There are several aspects where the impact of COVID-19 could be visualized. Among these, one aspect is the productivity of researcher, which plays a significant role in the success of an organization. Problem: There are several factors that could be aligned with the researcher's productivity of each domain and whose analysis through researcher's feedback could be beneficial for decision makers in terms of their decision making and implementation of mitigation plans for the success of an organization. Method: We perform an empirical study to investigate the substantial impact of COVID-19 on the productivity of researchers by analyzing the relevant factors through their perceptions. Our study aims to find out the impact of COVID-19 on the researcher's productivity that are working in different fields. In this study, we conduct a questionnaire-based analysis, which included feedback of 152 researchers of certain domains. These researchers are currently involved in different research activities. Subsequently, we perform a statistical analysis to analyze the collected responses and report the findings. Findings: The results indicate the substantial impact of COVID-19 pandemics on the researcher's productivity in terms of mental disturbance, lack of regular meetings, and field visits for the collection of primary data. Conclusion: Finally, it is concluded that researcher's daily or weekly meetings with their supervisors and colleagues are necessary to keep them more productive in task completion. These findings would help the decision makers of an organization in the settlement of their plan for the success of an organization.
\end{abstract}

Keywords: COVID-19; researchers; productivity; statistical analysis 


\section{Introduction}

The COVID-19 epidemic started in Wuhan, China at the end of 2019. After a few months, this epidemic was declared as a pandemic by the World Health Organization (WHO) [1-3] as it caused several deaths around the globe. Furthermore, it affected millions of people in several sectors such as, education, financial and healthcare. The COVID-19 infected 52,066,14 people throughout the globe in less than 3 months and became the reason for several deaths in 216 countries and regions (WHO) [3]. On the other hand, several organizations around the globe have offered their employees the choice to work from home to maintain the social distancing [4]. In the early months of COVID-19 on certain taking a toll on human lives including dire financial strains on communities and households, the World Health Organization (WHO) acknowledged COVID-19 as a global pandemic [5]. To overcome this situation, each country establishes the guidelines for the precaution and awareness of their people. Moreover, the adaptation of novel ways to analyze and visualize the impact of infectious pandemics always remains a challenge for healthcare research community. The research community has reported that besides other side effects, COVID-19 has changed the working mode of employees of certain domains such as in academia, software industries and productivity of researchers [4].

In our knowledge, there is no study that is performed to analyze the impact of infectious pandemics (Such as COVID-19) on the research productivity (in terms of change in their working mode) of researchers of numerous domains. Specially, the research work of societal and behavioral discipline communities has been affected due COVID-19 in many dimensions such as for data collection and field visit. Even most of the institutes are giving allowances on research projects supervisors to accommodate their researchers who are now incapable to gather research data to meet the deadlines which has been delayed due to COVID-19 [6]. At the moment, there are no proper guidelines from the state of affairs for the research communities especially problemoriented research communities where gathering of primary data is quite necessary to complete the research task by meeting deadlines. In this regards, several higher education level institutes published their guidelines that how researchers could be involved in collecting primary data during COVID-19 pandemic [7,8]. However, few questions remain challenging for research communities whose investigation is mandatory such as what is the perception of researcher in accordance with, how COVID-19 pandemic has changed their working mode (i.e., impact on their research productivity), what sort of support they need to perform their research task smoothly, and so on. By keeping our eyes on such motivation, we conduct an empirical study by collecting feedback of 152 researchers through a questionnaire-based analysis.

The findings of the impact of COVID-19 on the research productivity could be quite beneficial for the research supervisors, research-oriented planning and the development organizations. Furthermore, it is also beneficial to the individual researcher to manage the project completion deadlines and budget to accommodate their team members effectively. In order to achieve this research objective, we formulate the following research questions.

Research Question 1 (RQ-1): How COVID-19 pandemic affected the researchers' productivity with respect to their demographic information?

Research Question 2 (RQ-2): Which factors are affecting the research productivity of researchers?

Research Question 3 (RQ-3): Which critical factors are more influencing the researchers' productivity? 


\section{Related Work}

The raise of COVID-19 from Wuhan, China brings several challenges not only for the communities but also for the country level organizations. These challenges include lack of proper guidelines such as how to face the issue in terms of monitoring and controlling, what type of precaution should be adopted, and what type of cure strategies should be adopted for infected people. In this regard, Singh et al. [1] conducted a study and reported the issue of a rapid increase in infected (Positive case of COVID-19) cases. On the other hand, authors also reported the outbreak of substantial psychological effect COVID-19 in UK. The UK government used the media as a way to inform their people about the raising impact of COVID-19.

Lima et al. [4] conducted a study to report the impact of COVID-19 on the emotional wellbeing of people as compared to their normal working behavior while working in social variations. In this regard, authors reported the terrible need for organizations to quickly invest in developing vigorous ordinal infrastructure [4].

In a recent study, Kazmi et al. [7] performed a study by considering a variety of psychosomatic and emotional responses about anxiety and ambiguity, and investigate the impact of COVID-19 on the mental health issues. Moreover, the authors reported the effect of lockdown on the mental health of researchers of several domains. Moreover, the authors evaluated "Depression," "Anxiety" and Tension of approximately 1000 responses and report the major alteration between "Depression," "Anxiety" and "Stress" in this pandemic situation and previous normal situation.

Metzler [6] investigated the effect of COVID-19 on the routine life of researchers who are involved in collection of primary data. The author reported that new ways of working are confusing, where COVID-19 affect every ground of life it has also effected several research communities. Research projects in the social and behavioral disciplines are reexamined in many cases. Many organization/institutes are giving allowances on research projects and thesis to controllers to accommodate researchers who are now incapable to gather research data and delayed in deadlines due to COVID-19. According to the findings of Global Research firm Gartner, organizations are dependent on technology to allow teams to work remotely. There is a rising demand for virtual workstation resolutions that aid employees to endure to work together, interconnect, and normally. As a group, their meetings are transferred to conference calls like Skype, Zoom and so on [8].

There are several applications that are accessible to allow researchers/professionals to work remotely such as Google Docs, MS Teams, Hangouts, Zoom and Skype for steady communication. However, it is still necessary to be emotionally and socially prepared for this new norm [9]. In a related study, the authors reported that during COVID-19, professionals are familiar with new norm where small home-based workplace could be customized [10]. In such situation, differentiation between the work boundaries is quite necessary among professional and individual lives for good mental fitness [11]. In their study, Laura et al. [12] reported the borders among individuals and professionals, the time period is obscuring in a novel and rare way through the abrupt evolution to work remotely. Days are merging with night and weekdays are blending with weekend. Nickson et al. [13] have given suggestions on how to handle this new situation of continuous work remotely. They stated that professionals must have accurate proficiency to deal with this new norm. This will aid professionals to inaugurate steadiness among research and personal life.

In remote working method, researchers spend less time on research [14]. Subsequently, Chamorro-Premuzic's study also supported this finding [15]. According to the Thompson [16], 
there are several factors that affect research productivity such as theoretical, ethical, and practical factors.

Many studies have confirmed the effect of COVID-19 outbursts on community mental health. Previous studies like severe acute respiratory syndrome (SARS) in 2003 [17-19] and in 2009 novel influenza A (HIN1) widespread [20-23]. These types of pandemics lead to psychological problems such as mental stress, depression, and anxiety [24,25]. According to a hypothetical model of Ehlers et al. [26], it is confirm that after suffering from a disturbing incident, persons may make an adverse assessment of the pain. Therefore, they certainly accept maladaptive strategies to sustain Post-traumatic stress disorder PTSD symptoms like assault and strong destructive emotions [27-30].

In our study, we find out the impact of COVID-19 on research productivity of researchers of several domains by conducting an empirical analysis on the feedback of 152 respondents.

\section{Proposed Methodology}

The purpose of this study is to explore the impact of COVID-19 on research productivity (in terms of an alteration in their work-mode) of researchers who are working in different domains. We conduct an empirical study with the help of a vivid survey method to collect feedback of researchers who have experienced their research activities during COVID-19 era. Subsequently, we performed analysis through different statistical test and reports the results accordingly. Overview of our proposed methodology is shown in Fig. 1.

\subsection{Data Analysis}

Initially, the online questionnaire ${ }^{1}$ disseminate to more than 200 active researchers of several universities and research organization of different domains. Without gender discrimination, we collect the response of 152 respondents. Besides the demographic information, mostly questions of the questionnaire are of closed-form to know about the respondent feedback in the form of Lickert Scale as shown in Appendix A.

\subsection{Statistical Analysis}

After collecting data, we performed frequency analysis to describe the strength of populations and apply $t$-tests to benchmark the findings. Moreover, a descriptive statistics is presented to benchmark the findings of certain populations.

\subsection{Result Dissemination}

We present results in two fold. Firstly, we describe some data distribution between responses of certain groups. Secondly, we emphasized the factors through the researchers' feedback that could affect their productivity.

\footnotetext{
1 https://docs.google.com/forms/d/16qxJi8kbqTGlfASpSfACw2G-1esBsIMjzFj6md-1u5U/edit?gxids=7628.
} 


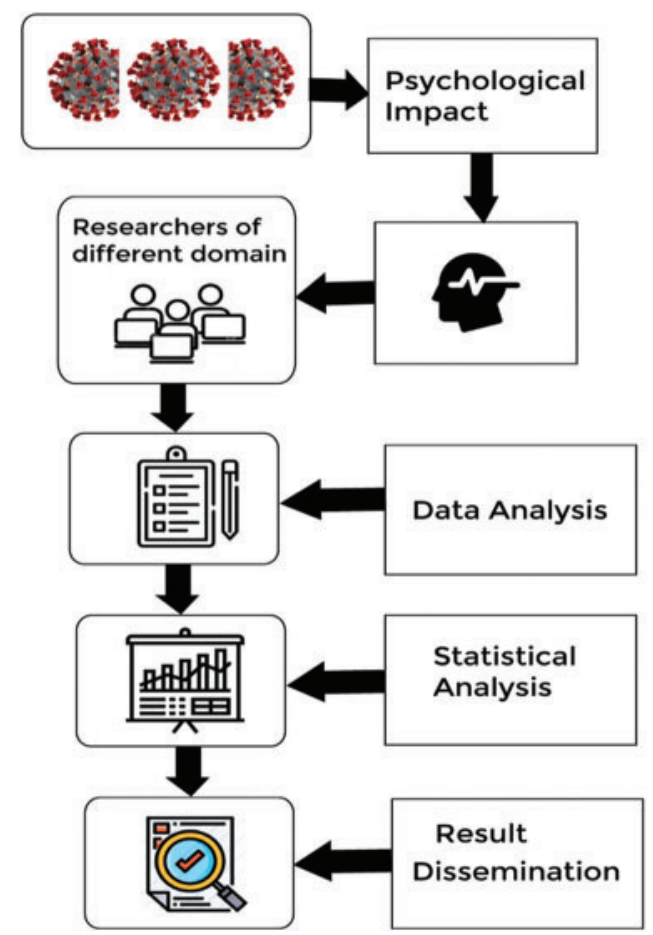

Figure 1: Overview of the proposed methodology

\section{Result Discussions}

The aim of proposed study is to investigate the impact of COVID-19 on the productivity of researchers through their perception/feedback. Subsequently, we analyzed the factors which could affect the researchers' productivity.

\section{Response to RQ-1:}

In order to respond RQ-1, firstly we collect the information about researcher's perception about the impact of COVID-19 on their research productivity. In this regard, we performed frequency analysis and present results with respect to the researcher's corresponding demographic information as shown in Tab. 1. The first column describes the variables which are used to record the demographic information of researchers who have participated in this study. The second column of Tab. 1 describes the possible outcomes of each variable. For example, Gender variable is used to present two outcomes namely Male and Female. The third and fourth columns are used to describe the perception of researchers, i.e., either Yes or No about the effect of COVID-19 on their research productivity. For example, 52 (See in Column 3) out of 82 (sum of Column 3 and 4) male researchers are showing their perception that COVID-19 has an effect on their research productivity. The fifth column describes the outcome-based percentage $(100 \%$ in sum) of each variable. For example, $53.94 \%$ male and $46.06 \%$ female are participated out of the total sample size (i.e., $\mathrm{N}=152$ ). Finally, the last column indicates the percentage those researchers whose response was yes about the effect of COVID-19 on their performance. For example, 70.73\% (i.e., 52/82) of total male (i.e., Male Researchers $=82$ ) are recorded their response as yes about the effect of COVID-19 pandemic on their research productivity.

The main consequences of Tab. 1 are as follow. 
Table 1: Descriptive statistics for COVID-19 effect on researchers' productivity

\begin{tabular}{|c|c|c|c|c|c|}
\hline \multirow[t]{2}{*}{ Variable } & \multirow[t]{2}{*}{$\begin{array}{l}\text { Variable's } \\
\text { outcomes }\end{array}$} & \multicolumn{2}{|c|}{$\begin{array}{l}\text { COVID-19 effect } \\
\text { on researcher's } \\
\text { productivity }\end{array}$} & \multirow[t]{2}{*}{$\begin{array}{l}\text { Outcomes based } \\
\text { percentage }(\%)\end{array}$} & \multirow[t]{2}{*}{$\begin{array}{l}\text { Percentage who } \\
\text { response Yes }(\%)\end{array}$} \\
\hline & & Yes & No & & \\
\hline \multirow[t]{2}{*}{ Gender } & Male & 52 & 30 & 53.94 & 70.73 \\
\hline & Female & 35 & 35 & 46.06 & 50.00 \\
\hline \multirow[t]{4}{*}{ Age } & $21-30$ & 90 & 20 & 72.37 & 81.81 \\
\hline & $31-40$ & 30 & 12 & 27.73 & 71.42 \\
\hline & $41-50$ & 00 & 00 & 00.00 & 00.00 \\
\hline & Above 50 & 00 & 00 & 00.00 & 00.00 \\
\hline \multirow{9}{*}{ Country } & Pakistan & 75 & 10 & 55.92 & 88.22 \\
\hline & America & 05 & 05 & 06.57 & 50.00 \\
\hline & China & 15 & 10 & 16.44 & 60.00 \\
\hline & India & 10 & 05 & 09.86 & 66.66 \\
\hline & Ireland & 04 & 03 & 04.65 & 57.14 \\
\hline & UK & 01 & 01 & 01.31 & 50.00 \\
\hline & Turkey & 00 & 00 & 00.00 & 00.00 \\
\hline & Netherland & 00 & 00 & 00.00 & 00.00 \\
\hline & Others & 05 & 03 & 05.25 & 62.50 \\
\hline \multirow[t]{5}{*}{ Organization } & University & 85 & 06 & 59.86 & 93.40 \\
\hline & Software & 32 & 08 & 26.31 & 80.00 \\
\hline & Industry & 17 & 04 & 13.83 & 80.95 \\
\hline & Other & & & & \\
\hline & Organization & & & & \\
\hline \multirow[t]{4}{*}{ Current status } & Graduation & 66 & 10 & 50.00 & 86.84 \\
\hline & Junior level & 50 & 06 & 36.84 & 89.28 \\
\hline & researchers & 04 & 16 & 13.16 & 20.00 \\
\hline & $\begin{array}{l}\text { Senior level } \\
\text { researchers }\end{array}$ & & & & \\
\hline \multirow[t]{4}{*}{ Experience } & Less than 1 year & 32 & 04 & 23.68 & 88.88 \\
\hline & 1 to 3 years & 80 & 07 & 57.25 & 91.95 \\
\hline & 4 to 6 years & 20 & 03 & 15.13 & 86.95 \\
\hline & $\begin{array}{l}\text { More than } 6 \\
\text { years }\end{array}$ & 05 & 01 & 03.94 & 83.33 \\
\hline
\end{tabular}

- We observe the research productivity of male researchers (i.e., 70.73\%) is affected as compared to female researchers (i.e., $50.00 \%$ ).

- We cannot collect the feedback of the researchers whose age is greater than 40 , which can be considered as a threat of our proposed study. In a subsequent study, their responses can be altered by our current finding.

- We observe the high percentage of those researchers who belong to Pakistan and believe that their research productivity is highly affected by COVID-19. The lack of digital resources and internet facility could be the main factors behind their perception. 
- We observe mostly response (i.e., 85) from the university level researchers as compared to industry level researcher. Though, it is good sign for our findings but in future the feedback of industrial researcher could be more beneficial.

- Though we observe more response of graduate level researcher (i.e., 76) as compared to junior-level researchers (i.e., 56). However, we observe that junior level researchers are showing more belief as compared to graduate-level that their research productivity is affected due to COVID-19.

- We observe the research productivity of researchers of all experience level is affected due to COVID-19 as shown in at the end of last row of Tab. 1.

\section{Response to RQ-2:}

In order to respond RQ-2, we collect the researcher's feedback about the factors which could affect their research productivity. We extracted these factors from literature and through empirical study; we collect the researcher's feedback. We performed frequency analysis to record and present the information about factors affecting the researchers' productivity. Moreover, we differentiate the researchers' feedback gender-wise. For example, in case of factor (F1: Lack of Internet Resources), 22 out of 82 males (i.e., $22 / 82 \times 100=26.82 \%)$ while 23 out of 70 female $(23 / 70 \times 100=32.85 \%)$ who shows their willingness either as agree or strongly agree about the factor F1. Collectively (i.e., male and female participants), $29.60 \%$ (i.e., $45 / 152 \times 100$ ) researchers are agree that their research task are affected due to lack of internet resources and they faced issue to complete project on time. The result of researchers' feedback about factors affecting their research productivity is shown in Tab. 2. The main consequences of researchers' feedback about factors are as follows.

- In the case of factor F2 (i.e., Lack of training new ICT tool), we observed $68.42 \%$ (i.e., $104 / 152 \times 100)$ researchers are either disagree or strongly disagree, which shows the good interest and familiarity of researchers in new ICT tools.

- We observed $52.63 \%(80 / 152 \times 100)$ researchers are agree that during COVID-19 no support or guidance (i.e., F3) is provided form their host organizations, which could be alarming in case of prolong in COVID-19. There is need of each organization to publish guidelines to support their researchers to complete their research effectively and on time.

- We observed that $59.86 \%$ (i.e., $91 / 152 \times 100$ ) researchers think that COVID-19 has affected their health (i.e., F4) while 59.21 (i.e., $90 / 152 \times 100$ ) researchers believe that their anxiety and depression (i.e., F5) has been increased.

- We observed that 53.94 (i.e., 82/152 × 100) research could not access digital repositories (i.e., F6) to complete their research tasks. Consequently, beside guidance, each host organization needs to provide the access of digital repositories.

- Though, a huge number of $67.76 \%$ (i.e., $103 / 152 \times 100$ ) researchers were agree that their meeting with supervisors and colleagues is affected (i.e., F8). However, limited number of researchers (i.e., $39 / 152 \times 100=25.65 \%$ ) can manage time (i.e., F7) and $61.84 \%$ (i.e., $94 / 152 \times 100$ ) could not complete their research task in due time (i.e., F9).

- We observed only $38.81 \%$ (i.e., $59 / 152 \times 100$ ) were agree about the opportunity of new research grant (i.e., F10) is affected due to COVID-19, which is a good sign that higher education or international organization are providing research funding. We observed that $65.13 \%$ (i.e., $99 / 152 \times 100$ ) researchers are agree that they are facing issue in collecting data (i.e., F11) during COVID-19 era, which lead to the need of $55.26 \%$ (i.e., $84 / 152 \times 100$ ) researcher for the training how to collect data related to the field visit. 
Table 2: List of factors affecting researchers' productivity and researchers' feedback

\begin{tabular}{|c|c|c|c|c|c|c|}
\hline \multirow[t]{2}{*}{ Factors } & \multirow[t]{2}{*}{ Descriptions } & \multicolumn{5}{|c|}{ Researcher's response regarding Factors } \\
\hline & & $\begin{array}{l}\text { Strongly } \\
\text { disagree }\end{array}$ & Disagree & Neutral & Agree & $\begin{array}{l}\text { Strongly } \\
\text { agree }\end{array}$ \\
\hline \multirow[t]{2}{*}{ F1 } & \multirow[t]{2}{*}{ Lack of internet resources. } & Male 25 & 15 & 20 & 12 & 10 \\
\hline & & $\begin{array}{l}\text { Female } \\
20\end{array}$ & 10 & 17 & 10 & 13 \\
\hline \multirow[t]{2}{*}{$\mathrm{F} 2$} & \multirow[t]{2}{*}{ Lack of training of new ICT tool. } & Male 45 & 19 & 9 & 7 & 2 \\
\hline & & $\begin{array}{l}\text { Female } \\
30\end{array}$ & 10 & 5 & 8 & 17 \\
\hline \multirow[t]{2}{*}{ F3 } & \multirow[t]{2}{*}{ Lack of guidance from your host institute. } & Male 19 & 10 & 7 & 23 & 23 \\
\hline & & $\begin{array}{l}\text { Female } \\
11\end{array}$ & 16 & 9 & 14 & 20 \\
\hline \multirow[t]{2}{*}{ F4 } & \multirow[t]{2}{*}{ COVID-19 affected your health. } & Male 7 & 11 & 17 & 17 & 30 \\
\hline & & $\begin{array}{l}\text { Female } \\
6\end{array}$ & 10 & 10 & 16 & 28 \\
\hline \multirow[t]{2}{*}{ F5 } & \multirow{2}{*}{$\begin{array}{l}\text { COVID-19 affected your mental health like } \\
\text { anxiety or depression. }\end{array}$} & Male 10 & 15 & 10 & 18 & 29 \\
\hline & & $\begin{array}{l}\text { Female } \\
7\end{array}$ & 11 & 9 & 20 & 23 \\
\hline \multirow[t]{2}{*}{ F6 } & \multirow{2}{*}{$\begin{array}{l}\text { Lack of access to digital repositories such } \\
\text { IEEE, ACM and so on. }\end{array}$} & Male 9 & 9 & 20 & 19 & 25 \\
\hline & & $\begin{array}{l}\text { Female } \\
11\end{array}$ & 17 & 7 & 17 & 21 \\
\hline \multirow[t]{2}{*}{ F7 } & \multirow{2}{*}{$\begin{array}{l}\text { Due to COVID- } 19 \text { you cannot manage time } \\
\text { for project completion. }\end{array}$} & Male 7 & 12 & 17 & 21 & 25 \\
\hline & & $\begin{array}{l}\text { Female } \\
11\end{array}$ & 9 & 8 & 14 & 28 \\
\hline \multirow[t]{2}{*}{ F8 } & \multirow{2}{*}{$\begin{array}{l}\text { Regular meetings/collaboration with } \\
\text { supervisors/colleagues/researchers have been } \\
\text { affected due to COVID-19. }\end{array}$} & Male 12 & 11 & 8 & 23 & 28 \\
\hline & & $\begin{array}{l}\text { Female } \\
9\end{array}$ & 3 & 6 & 22 & 30 \\
\hline \multirow[t]{2}{*}{ F9 } & \multirow{2}{*}{$\begin{array}{l}\text { Your assigned tasks are not completed on } \\
\text { deadline due to COVID- } 19 \text {. }\end{array}$} & Male 10 & 8 & 18 & 20 & 26 \\
\hline & & $\begin{array}{l}\text { Female } \\
9\end{array}$ & 5 & 8 & 20 & 28 \\
\hline \multirow[t]{2}{*}{ F10 } & \multirow{2}{*}{$\begin{array}{l}\text { Due to COVID- } 19 \text { pandemic, the sources for } \\
\text { new research project grants have been } \\
\text { affected. }\end{array}$} & Male 17 & 19 & 18 & 11 & 17 \\
\hline & & $\begin{array}{l}\text { Female } \\
15\end{array}$ & 11 & 13 & 17 & 14 \\
\hline \multirow[t]{2}{*}{ F11 } & \multirow{2}{*}{$\begin{array}{l}\text { You are facing problems in data collection of } \\
\text { your current research projects during } \\
\text { COVID-19. }\end{array}$} & Male 7 & 9 & 11 & 25 & 30 \\
\hline & & Female & 9 & 9 & 17 & 27 \\
\hline \multirow[t]{2}{*}{$\mathrm{F} 12$} & \multirow{2}{*}{$\begin{array}{l}\text { You need training sessions to collect data } \\
\text { using online resources rather than through } \\
\text { the field visit. }\end{array}$} & Male 16 & 13 & 11 & 19 & 23 \\
\hline & & $\begin{array}{l}\text { Female } \\
11\end{array}$ & 8 & 9 & 17 & 25 \\
\hline
\end{tabular}

\section{Response to RQ-3:}

In order to respond RQ-3, we collect the researchers' feedback regarding their perception as Agree and Strongly Agree in terms of factors affecting their research productivity. For example, in case of factor F1 (i.e., Lack of Internet Resources) total of 45 researchers feedbacks (out of 152 total responses) which is equal to $29.26 \%$ of total population. In the same pattern, we assess 
the frequency and percentage of each factor with respect to "Agree and Strongly Agree" feedback of researcher. The results are shown in Tab. 3. The main consequences are as follows.

Table 3: Ranking of factors with respect to researchers' perceptions

\begin{tabular}{|c|c|c|c|c|}
\hline Factors & Description & Frequency & Percentage $(\%)$ & Rank\# \\
\hline F1 & Lack of internet resources. & 45 & 29.26 & 11 \\
\hline $\mathrm{F} 2$ & Lack of training of new ICT tool. & 34 & 22.36 & 12 \\
\hline F3 & Lack of guidance from your host institute. & 80 & 52.63 & 9 \\
\hline F4 & COVID-19 affected your health. & 91 & 59.86 & 4 \\
\hline F5 & $\begin{array}{l}\text { COVID-19 affected your mental health like } \\
\text { anxiety or depression. }\end{array}$ & 90 & 59.21 & 5 \\
\hline F6 & $\begin{array}{l}\text { Lack of access to digital repositories such IEEE, } \\
\text { ACM and so on. }\end{array}$ & 82 & 53.94 & 8 \\
\hline F7 & $\begin{array}{l}\text { Due to COVID- } 19 \text { you cannot manage time for } \\
\text { project completion. }\end{array}$ & 88 & 57.89 & 6 \\
\hline $\mathrm{F} 8$ & $\begin{array}{l}\text { Regular meetings/collaboration with } \\
\text { supervisors/colleagues/researchers have been } \\
\text { affected due to COVID-19. }\end{array}$ & 103 & 67.76 & 1 \\
\hline F9 & $\begin{array}{l}\text { Your assigned tasks are not completed on } \\
\text { deadline due to COVID- } 19 \text {. }\end{array}$ & 94 & 61.84 & 3 \\
\hline F10 & $\begin{array}{l}\text { Due to COVID-19 pandemic, the sources for } \\
\text { new research project grants have been affected. }\end{array}$ & 59 & 38.81 & 10 \\
\hline F11 & $\begin{array}{l}\text { You are facing problems in data collection of } \\
\text { your current research projects during COVID- } 19 \text {. }\end{array}$ & 99 & 65.13 & 2 \\
\hline F12 & $\begin{array}{l}\text { You need training sessions to collect data using } \\
\text { online resources rather than through } \\
\text { the field visit. }\end{array}$ & 84 & 55.26 & 7 \\
\hline
\end{tabular}

- We observed factor F8 with highest percentage value (i.e., $67.76 \%$ and Rank as number 1) that indicate that the researcher's productivity is highly affected due to irregular meeting with their research supervisors and colleagues.

- We observed factor F2 with lowest percentage (i.e., 22.36\% and Rank as number 12) that indicate researchers' productivity is not affected so much which present the researchers' familiarity with new ICT tool usage and they don't need some sort of training.

- The critical factors of researchers' productivity could be selected on the bases of percentage threshold of their feedbacks. For example, if we select $60 \%$ threshold of researchers' feedback then we can observe F8, F9, and F11 as critical factors that are affecting researchers' productivity.

We have reported the results of demographic information based distribution of impact on the researchers' productivity and related factors. Moreover, these results would help each organization who is feeling that their researchers are performing well as compared to their earliest performance by targeting the factors and make arrangements to resolve their issues. 


\section{Conclusions}

The experimental results of proposed empirical study are effective for organizations who are observing the productivity of their researchers. Several studies showed that productivity of their researchers is not same as their earlier before COVID-19. We conducted the questionnaire-based study to collect feedback of 152 researchers to know their perception about their research productivity in the era of COVID-19 and investigate the related factors. We performed analysis through statistical analysis techniques such as frequency analysis. Firstly, we reported that during COVID19 how research productivity of researchers with respect to their demographic information such as Gender, age, country, and job status wise. Secondly, we reported the researchers' perceptions about the factors related to the research productivity. Finally, we reported the critical factors which need to be emphasized by an organization whenever they feel the decline in the performance of their researchers. The main consequences of empirical studies are; (1) we observed research productivity is less effected due to usage and training of new ICT tools which shows the familiarity and interest of researchers to adopt new tools, (2) We observe the research community believes that regular meetings with their supervisors and colleagues are required to keep them more productive in the completion of their assigned tasks, (3) each organization could emphasize the factors and adopt mitigating strategies to improve the productivity whenever they feel decline in performance of researchers.

Funding Statement: The author(s) received no specific funding for this study.

Conflicts of Interest: The authors declare that they have no conflicts of interest to report regarding the present study.

\section{References}

[1] C. K. T. Lima, P. M. De Medeiros Carvalho, I. A. S. De Lima, J. V. A. De Oliveira Nunes, J. S. Saraiva et al., "The emotional impact of coronavirus 2019-nCoV (new Coronavirus disease)," Psychiatry Research, vol. 287, 112915, 2020.

[2] N. Y. University, "Researchers offer ways to address life under COVID-19," Science Daily, 2020. [Online]. Available: https://phys.org/news/2020-04-ways-life-covid-.html.

[3] T. A. Ghebreyesus, "Coronavirus disease (COVID-19) pandemic," WHO, 2020. [Online]. Available: https://www.who.int/emergencies/diseases/novel-coronavirus-2019.

[4] M. K. Singh and V. Kumar, "Impact of COVID-19 pandemic on working culture: An exploratory research among information technology (IT) professionals in Bengaluru," Karnataka (India), Journal of Xi'an University of Architecture and Technology, vol. 12, no. 5, pp. 3176-3184, 2020.

[5] J. Ducharme, "World health organization declares COVID-19 a 'pandemic.' here's what that means," 2020. [Online]. Available: https://time.com/5791661/who-coronavirus-pandemic-declaration/.

[6] A. V. K. Metzler, "How will COVID-19 impact student research projects," TIME, 2020. [Online]. Available: https://ocean.sagepub.com/blog/skills/how-will-COVID-19-impact-student-research-projects.

[7] P. Angelique, "The future of remote work after COVID-19: 3 common predictions," 2020. [Online]. Available: https://www.ekoapp.com/blog/the-future-of-remote-work-after-COVID-19-3-common-predictions.

[8] S. S. H. Kazmi, K. Hasan, S. Talib and S. Saxena, "COVID-19 and lockdown: A study on the impact on mental health. SSRN 3577515, 2020.

[9] T. Chadha, "COVID-19: Impact on organizational culture," BW People, 2020. [Online]. Available: http://bwpeople.businessworld.in/article/COVID-19-Impact-On-Organizational-Culture/15-04-2020$189253 /$. 
[10] N. Sharma, "Indian it firms' COVID-19 working model is here to stay," Bloomberg, 2020. [Online]. Available: http://www.bloombergquint.com/coronavirus-outbreak/indian-it-firms-covid-19-working-modelis-here-to-stay.

[11] K. Venessa, M. Laura Bonns and Giurge, "3 tips to avoid wfh burnout," Harvard Business Review, 2020, [Online]. Available: https://hbr.org/2020/04/3-tips-to-avoid-wfh-burnout.

[12] E. Y. C. Peng, M. B. Lee, S. T. Tsai, C. C. Yang, D. E. Morisky et al., "Population-based postcrisis psychological distress: An example from the SARS outbreak in Taiwan," Journal of the Formosan Medical Association, vol. 109, pp. 524-532, 2010.

[13] D. Nicdon and S. Siddons, "Remote working: Linking people and organization," Industrial and Commercial Training, vol. 36, no. 2, pp. 86-87, 2004.

[14] K. Venessa, M. Laura Bonns and Giurge, "1-3 tips to avoid wfh burnout," Harvard Business Review, 2020. [Online]. Available: https://hbr.org/2020/04/3-tips-to-avoid-wfh-burnout.

[15] E. Dhawan and T. Chamorro-Premuzic, "How to collaborate effectively if your team is remote," Harvard Business Review, 2018.

[16] K. Thompson, "Factors affecting choice of research method," 2016. [Online]. Available: https://revisesociology.com/2016/01/05/factors-affecting-choice-of-research-methods/.

[17] M. B. Omary, J. Eswaraka, S. D. Kimball, P. V. Moghe, R. A. Panettieri et al., "The COVID-19 pandemic and research shutdown: Staying safe and productive," The Journal of Clinical Investigation, vol. 130, no. 6, pp. 2745-2748, 2020.

[18] C. H. Ko, C. F. Yen, J. Y. Yen and M. J. Yang, "Psychosocial impact among the public of the severe acute respiratory syndrome epidemic in Taiwan," Psychiatry and Clinical Neurosciences, vol. 60, pp. 397403, 2006.

[19] L. Liang, H. Ren, R. Cao, Y. Hu, Z. Qin et al., "The effect of COVID-19 on youth mental health," Psychiatric Quarterly, pp. 1-12, 2020.

[20] N. C. Yeung, J. T. Lau, K. C. Choi and S. Griffiths, "Population responses during the pandemic phase of the influenza A (H1N1) pdm09 epidemic, Hong Kong, China," Emerging Infectious Diseases, vol. 23, pp. 813, 2017.

[21] S. Hussain, J. Keung and A. A. Khan, "Software design patterns classification and selection using text categorization approach," Applied Soft Computing, vol. 58, pp. 225-244, 2017.

[22] S. Hussain, J. Keung, M. K. Sohail, M. Ilahi and A. A. Khan, "Automated framework for classification and selection of software design patterns," Applied Soft Computing, vol. 75, pp. 1-20, 2019.

[23] S. A. Taha, K. Matheson and H. Anisman, "H1N1 was not all that scary: Uncertainty and stressor appraisals predict anxiety related to a coming viral threat," Stress and Health, vol. 30, pp. 149-157, 2014.

[24] J. M. Shultz, F. Baingana and Y. Neria, "The 2014 ebola outbreak and mental health: Current status and recommended response," Jama, vol. 313, pp. 567-568, 2015.

[25] E. Smit, "Mental health problems among students," Vrije Universiteit Amsterdam, 2015. [Online]. Available: https://www.huisartsenamsterdam.n1/wp-content/uploads/2015/08/Research-report-E.-Smit-1707-2015.pdf.

[26] A. Ehlers and D. M. Clark, "A cognitive model of posttraumatic stress disorder," Behaviour Research and Therapy, vol. 38, pp. 319-345, 2000.

[27] W. Xu, G. Fu, Y. An, G. Yuan, X. Ding et al., "Mindfulness, posttraumatic stress symptoms, depression, and social functioning impairment in Chinese adolescents following a tornado: Mediation of posttraumatic cognitive change," Psychiatry Research, vol. 259, pp. 345-349, 2018.

[28] S. Hussain, H. Afzal, M. R. Mufti, M. Imran, A. Ali et al., "Mining version history to predict the class instability," PLoS One, 2019.

[29] S. Tariq, N. Akhtar, H. Afzal, S. Khalid, M. R. Mufti et al., "A novel co-training-based approach for the classification of mental illnesses using social media posts," IEEE Access, vol. 7, pp. 166165$166172,2019$.

[30] S. Hussain, M. R. Mufti, M. K. Sohail, H. Afzal, G. Ahmed et al., "A step towards the improvement in the performance of Text classification," KSII Transactions on Internet and Information Systems, vol. 13, no. $4,2019$. 


\section{Appendix A}

Questionnaire Description: COVID-19 has caused a substantial impact on several perspectives of individual lives such as economics, education, learning, mental health, and social norms. The productivity of the research community in numerous domains is influenced by several factors such as knowledge transfer, access to resources, mental satisfaction, and social norms. The aim of this questionnaire is to analyze the role of COVID-19 to influence the research productivity of researchers of several domains.

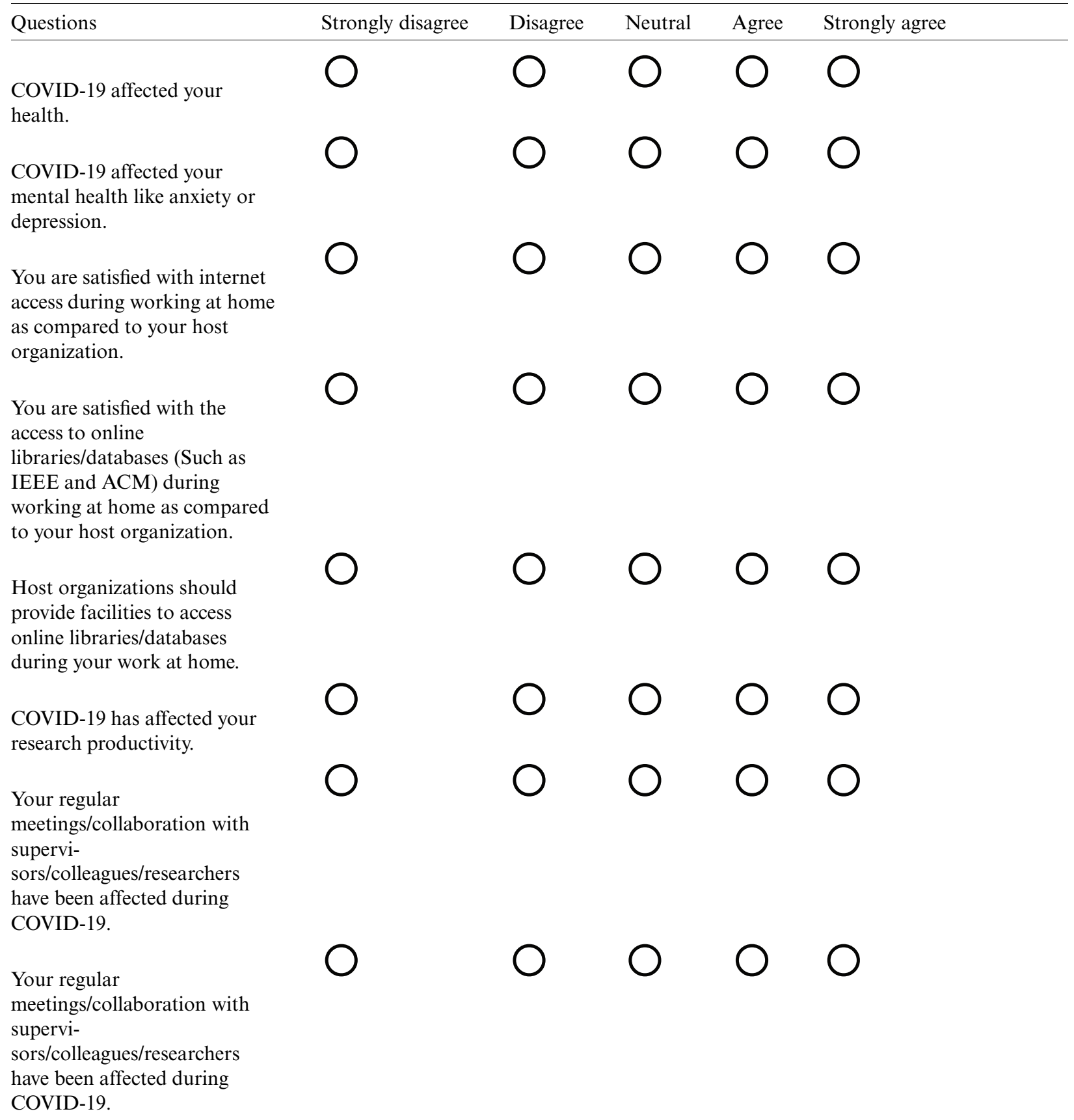


CMC, 2021, vol.67, no.2

\section{(Continued)}

\begin{tabular}{|c|c|c|c|c|c|}
\hline Questions & Strongly disagree & Disagree & Neutral & Agree & Strongly agree \\
\hline $\begin{array}{l}\text { Lack of guidance from your } \\
\text { host institute affect research } \\
\text { productivity. }\end{array}$ & & & & & \\
\hline $\begin{array}{l}\text { Lack of availability of internet } \\
\text { affect research productivity. }\end{array}$ & & & & & \\
\hline $\begin{array}{l}\text { Lack of ICTs skills affect } \\
\text { research productivity. }\end{array}$ & & & & & \\
\hline $\begin{array}{l}\text { COVID-19 has affected your } \\
\text { emphasis to complete the } \\
\text { research task within the given } \\
\text { deadline. }\end{array}$ & & & & & \\
\hline $\begin{array}{l}\text { In your opinion, due to } \\
\text { COVID- } 19 \text { researchers have } \\
\text { not been able to complete the } \\
\text { research task. }\end{array}$ & & & & & \\
\hline $\begin{array}{l}\text { In your opinion, during the } \\
\text { COVID-19 pandemic, the } \\
\text { sources for new research } \\
\text { project grants have been } \\
\text { affected. }\end{array}$ & & & & & \\
\hline $\begin{array}{l}\text { You are facing problems in } \\
\text { data collection of your current } \\
\text { research projects during } \\
\text { COVID-19. }\end{array}$ & & & & & \\
\hline $\begin{array}{l}\text { Your supervisor or top-level } \\
\text { management helping you to } \\
\text { resolve the issue of data } \\
\text { collection during COVID-19. }\end{array}$ & & & & & \\
\hline $\begin{array}{l}\text { You need training sessions to } \\
\text { collect data using online } \\
\text { resources rather than through } \\
\text { the field visit. }\end{array}$ & & & & & \\
\hline
\end{tabular}

